\title{
Thermal performance measurement and application of a multilayer insulator for emergency architecture
}

\author{
Graziano Salvalai ${ }^{\text {a, }}{ }^{*}$, Marco Imperadori a , Diego Scaccabarozzi ${ }^{\text {, }}$, Cristina Pusceddu ${ }^{\text {a }}$ \\ ${ }^{a}$ Department of Architecture, Built Environment and Construction Engineering, Politecnico di Milano, Milan, 20133, Italy \\ ${ }^{\mathrm{b}}$ Department of Mechanical Engineering, Politecnico di Milano, Milan, Italy
}

\begin{abstract}
Lightness coupled with a quick assembly method is crucial for emergency architecture in post-disaster area where accessibility and action time play a huge barer to rescue people. In this prospective, the following work analyses the potentiality (technological and thermal performances) of multilayer insu-lator for a new shelter envelope able to provide superior thermal comfort for the users. The thermal characteristics are derived experimentally by means of a guard ring apparatus under different working temperatures. Tests are performed on the multilayer insulator itself and on a composite structure, made of the multilayer insulator and two air gaps wrapped by a polyester cover, which is the core of a new lightweight emergency architecture. Experimental results show good agreement with literature data, providing a thermal conductivity and transmittance of about $0.04 \mathrm{~W} /\left(\mathrm{m}{ }^{\circ} \mathrm{C}\right.$ ) and $1.6 \mathrm{~W} /\left(\mathrm{m}^{2}{ }^{\circ} \mathrm{C}\right)$ for the tested multilayer. The composite structure called Thermo Reflective Multilayer System (TRMS) shows better insulation performances, providing a thermal transmittance set to $0.85 \mathrm{~W} /\left(\mathrm{m}^{2}{ }^{\circ} \mathrm{C}\right)$. A thermal model of an emergency tent based on the new insulating structure (TRMS) has been developed and its thermal performances have been compared with those of a UNHCR traditional emergency shelter. The shelter model was simulated (Trnsys v.17 environment) in the winter season considering the climate of Belgrade and using only the casual gains from occupant and solar radiation through opaque wall. Nu-merical simulations evidenced that the new insulating composite envelope reduces required heating load of about two and four times with respect to the traditional insulation. The study sets a starting point to develop a lightweight emergency architecture made with a combination between multilayer, air, polyester and vulcanized rubber.
\end{abstract}

Keywords:

Thermo reflective multilayer

system Hot guarded plate

apparatus Thermal conductivity

Emergency architecture

\section{Introduction}

In the last years the total number of people displaced in the world has remained roughly constant at approximately 15 million refugees and a further 25 million internally. 2153 is the number of natural and artificial disasters which hit the world in the last 3 years [1]. About ninety thousands people are affected from these events

* Corresponding author. Tel.: +39 034148 8791, +39 022399

6013.

E-mail address: graziano.salvalai@polimi.it (G. Salvalai).
[2]. Disaster-affected households should no longer be treated as liabilities. This has significant implications on recommended approaches to post-disaster shelters and survivors of these crises must be given every opportunity to engage in their own recovery [3]. Low density materials like multilayers insulators or aerogel foams, thanks to their lightness and thermal performances, can be used to answer to the housing needs of victims ensuring technological, psychological performance and safety during disasters events. These materials are nowadays used in the civil area for normal construction or reconstruction processes [4-6], but were originally developed for passive thermal control in space 


$\begin{array}{ll}\text { Nomenclature } \\ \lambda_{\text {eq }} & \text { Thermal conductivity of multilayer and/or insulating } \\ & \text { structure }\left[\mathrm{W} /\left(\mathrm{m}^{\circ} \mathrm{C}\right)\right] \\ \phi & \text { Heat flow-rate through specimens }[\mathrm{W}] \\ \mathbf{q} & \text { Heat flux density }\left[\mathrm{W} / \mathrm{m}^{2}\right] \\ \mathbf{A} & \text { Specimen area }\left[\mathrm{m}^{2}\right] \\ \mathbf{t} & \text { Thickness of the insulating material }[\mathrm{m}] \\ \mathbf{T}_{\mathbf{h}} & \text { Central disk temperature }\left[{ }^{\circ} \mathrm{C}\right] \\ \mathbf{T}_{\mathbf{c}} & \text { Cold disk and plate temperatures }\left[{ }^{\circ} \mathrm{C}\right] \\ \mathbf{U}_{\mathbf{e q}} & \text { Transmittance of multilayer and } / \text { or insulating } \\ & \text { structure }\left[\mathrm{W} /\left(\mathrm{m}^{2}{ }^{\circ} \mathrm{C}\right)\right] \\ \mathbf{i}_{\mathbf{0}} & \text { Inner disk supply current }[\mathrm{A}] \\ \mathbf{V}_{\mathbf{0}} & \text { Inner disk supply voltage }[\mathrm{V}]\end{array}$

applications, in order to provide good insulating performances in vacuum condition [7-9]. Multilayer structure is generally made of metalized plastic films, typically polyamide for low temperature ranges or metallic foils for high temperature applications. Plastic films are separated by nets made of glass fibre, polyester or silk, which minimize heat conduction between the foils and avoid an extended contact. Multilayer effectiveness in vacuum lays in the low emissivity of the metalized surfaces limiting radiative heat exchange. Thus, the multilayer experienced thanks to its characteristics an increased usage in civil architecture to reduce energy consumption without affecting the thermal comfort. Multilayer for building application is more compact than traditional insulation technology but achieves similar performances [10], providing also an effective vapour barrier [11]. Moreover, the material structure is ordinarily non-irritant, non-asthmatic and non-allergenic, so that no protective clothing or equipment are necessary during assembly, installation and manufacturing. Because of the low emission coef-ficient of the foils, radiation through the insulation material is significantly reduced leading to very high thermal resistance, even up to $6 \mathrm{~m}^{2}{ }^{\circ} \mathrm{C} / \mathrm{W}$ [4]. The latter value was obtained by means of monitoring thermal performances in situ (test houses) but discus-sion about whether these claims are correct is still ongoing. Different studies have been performed to derive and compare multilayer performances in buildings. Normally the experimental tests are carried out with hot box and hot plate measurements, and the latter methods provide much more lower thermal resistances. Some examples can be found in the activity performed by the Building Research Establishment (BRE) [12], Alba Building Sciences [13], University of Reunion [14,15] and Dublin Institute of Tech-nology [16]. The results showed that multilayer thermal perfor-mances are influenced by the foils emissivity, heat flow direction, air cavities dimension [17]. Measured thermal resistances are be-tween 1.0 and $1.9 \mathrm{~m}^{2}{ }^{\circ} \mathrm{C} / \mathrm{W}$, depending on the heat flow direction, the type of multilayer and the presence of nonventilated cavities. Moreover, the thermal resistance generally increases adding reflective foils between the spacing nets and outside. In fact, tests performed with polyethylene films instead of reflective layers showed a general worsening of the insulating performances [4]. Comparison between laboratory experiments and test houses is provided in Ref. [18]. House testing was performed on two build-ings supposed to be identical. The first house was insulated with $210 \mathrm{~mm}$ mineral fibre in the roof installed between timber studs/rafters with known thermal resistance (of $5.2 \mathrm{~m}^{2}{ }^{\circ} \mathrm{C} / \mathrm{W}$ ) whereas the second one was equipped with a commercially available multilayer, i.e. the ACTIS TRISO Super 12 [10]. Environmental con-ditions were supposed to be identical, both in real or simulated

$\begin{array}{ll}\mathbf{T}_{\mathbf{a}} & \text { Multilayer average temperature }\left[{ }^{\circ} \mathrm{C}\right] \\ \Delta \mathbf{T} & \text { Temperature difference between } \mathrm{T}_{\mathrm{h}} \text { and } \mathrm{T}_{\mathrm{C}}\left[{ }^{\circ} \mathrm{C}\right] \\ \mathbf{p} & \text { Multilayer interstitial gas pressure }[\mathrm{Pa}] \\ \mathbf{R}_{\mathbf{R q}} & \text { Equivalent thermal resistance }\left[\mathrm{m}^{2}{ }^{\circ} \mathrm{C} / \mathrm{W}\right] \\ \mathbf{u}_{\mathbf{T c}} & \text { Uncertainty of the cold disk and plate temperatures } \\ & {\left[{ }^{\circ} \mathrm{C}\right]} \\ \mathbf{u}_{\mathbf{T h}} & \text { Uncertainty of the inner disk temperature }\left[{ }^{\circ} \mathrm{C}\right] \\ \mathbf{u}_{\Delta \mathbf{T}} & \text { Uncertainty of the temperature difference }\left[{ }^{\circ} \mathrm{C}\right] \\ \mathbf{u}_{\mathbf{V o}} & \text { Uncertainty of the inner disk voltage }[\mathrm{V}] \\ \mathbf{u}_{\mathbf{i} \mathbf{0}} & \text { Uncertainty of the inner disk current }[\mathrm{A}] \\ \mathbf{u}_{\phi \mathbf{t}} & \text { Uncertainty of the heat flow rate }[\mathrm{W}] \\ \mathbf{u}_{\mathbf{A}} & \text { Uncertainty of the disk area }\left[\mathrm{m}^{2}\right] \\ \left.\mathbf{u}_{\mathbf{t}}\right] & \text { Uncertainty of the multilayer and/or insulating } \\ & \text { structure thickness [m] }\end{array}$

conditions, and energy demand for maintaining a constant indoor temperature was monitored and finally compared to derive the multilayer thermal resistance. Results showed that the energy consumption of the test house with timber framed roof structure (with $210 \mathrm{~mm}$ of mineral wall) was equivalent to that one insulated with TRISO SUPER 12. Accuracy of the performed measurements lays on the equivalence between the testing workbenches (un-avoidable affected by air tightness of both test houses) and is related to the presence of ventilated and nonventilated air cavities or thermal bridges.

Thus, as also testified by literature data dispersion, prediction of multilayer thermal performances is generally critical and related to the measurement methods [4], to the multilayer structure (i.e. number of layers, spacers material) [7,19], to the environment (interstitial gas pressure and temperature) [8], and therefore, cannot exempt from an experimental characterization.

In this study the ACTIS TRISO Super 10 multilayer has been tested by means of a guard ring apparatus at $40^{\circ} \mathrm{C}$ and $60{ }^{\circ} \mathrm{C}$, i.e. simulating normal and worst operation conditions in view of developing an enhanced insulating system for emergency architecture.

The current UNHCR (United Nations Human Rights Council) policy [20] allows "survival conditions" inside winterized tents until a more suitable accommodation can be found, such as renovated buildings or more sophisticated (military type) heated tents. Several works about tent prototype and energy modelling of the emergency shelter are available in literature [21-27]. Ajam carried out a study of thermal comfort in low-cost adobe refugee shelter in hot and arid climate [21]. Manfield in Ref. [22] compared vernacular and purpose built shelter for cold climate use. Since 1998, experi-ments conducted by a team at the Martin Centre used wind tunnel, cold chamber and field testing to capture useful physical data. Manfield modelled a United Nation winter tent and a prototype shelter, finding that a tent relying only on casual gains from occu-pants, would eliminate the need of fuel burning stove and associ-ated fire risk. Crawford et al. [25] evaluated the thermal performance of emergency shelter systems by numerical simulations and experimental activity, highlighting that feasibility of heating the tent using casual gains is appropriate only in some locations and that issues related to the air stratification inside the tent may occur. Anyway, as stated by the authors, accuracy of the derived findings was limited by the lack of measurement about air infiltrations.

Batilana carried out tests on a temporary shelter and found an energy saving potential of about $76 \%$ respect to UNHCR cold climate refugee tent [26]. Flanders conducted test on air transportation tent 
for military use with particular attention to thermal comfort and fuel saving [27]. The study evidenced the need of highly insulated shelter, as an instance making it nearly airtight although in that case manufacturing cost increases.

In this context, the aim of this work is to evaluate the performance of proposed composite and very lightweight system, to highlight potential improvements with respect to the reference cold climate shelter based on UNHCR tent model. Thus, a thermal model based on the studied insulating structure has been developed by the authors to predict the thermal performance of a tent in the climate of Belgrade.

The paper is organized as follows: theoretical background, setup for thermal conductivity/conductance measurement and tested material and system are described in Section 2. Section 3 reports and discusses the testing results whereas Section 4 provides detailed description of an intended application for emergency architecture based on the composite structure, i.e. the Air Shelter panel. Thermal model of the Air Shelter and simulation results are described in Section 5 and Section 6 concludes the paper.

\section{Material and methods}

\subsection{Theoretical background}

Heat flux modelling through a multilayer specimen is complex task since heat exchange is generally driven by conduction, convection and radiation. Further difficulties can arise from the presence of three-dimensional temperature profiles, complex geometries and local additional heat paths due to slots, seams and stitching, needed to fix or shape the multilayer insulator (MLI). Thermal insulators performances are usually modelled using either the equivalent conductivity or the equivalent emissivity [7]. These parameters are used to predict insulators performances under the hypothesis that heat exchange through MLI specimen is respectively driven by conductance or radiation. The equivalent thermal conductivity $\lambda_{e q}$ can be identified once the extreme temperatures are measured together with heat flux density $q$ :

$\lambda_{e q}\left(p, T_{a}\right)=\frac{q t}{\left(T_{h}-T_{c}\right)}$

$T_{h}$ and $T_{c}$ are the temperatures at the hot (e.g. inner) and cold (e.g. outer) multilayer, $t$ is the sample thickness, $T_{a}$ is the average between $T_{h}$ and $T_{c}$ and $p$ is the interstitial gas pressure. Equation (1) is valid in steady state condition, i.e. when the heat flux through the specimen is constant. In a similar manner equivalent transmittance $U_{e q}$ can be derived as (Eq. (2)):

$U_{e q}\left(p, T_{a}\right)=\frac{q}{\left(T_{h}-T_{c}\right)}$

Inverting Equation (2) equivalent thermal resistance is found (Eq. (3)):

$R_{e q}\left(p, T_{a}\right)=\frac{1}{U_{e q}}$

The equivalent parameters depend on the average temperature $T_{a}$ and on the interstitial gas pressure $p$.

\subsection{Setup description and testing procedure}

Methods for the measurement of the thermal conductivity of insulating materials are classified as steady-state and transient methods [28-34]. Among the steady-state methods, the guarded- hot plate allows achieving accurate results, with uncertainty set to $1.5 \%$ over a limited temperature range near ambient [28].

The guarded-hot plate apparatus requires two identical specimens to guarantee symmetrical heat flow upwards and downwards according to the setup shown in Fig. 1. The instrument comprises two heaters packaged respectively into an aluminium circular disk and on an external annulus [8]. The central disk provides an adjustable heat flux through the tested specimens. The flux magnitude depends on the desired hot temperature $T_{h}$ and the external one $T_{c}$. Power of the external annulus is regulated to match the inner disk temperature avoiding any lateral heat exchange. In this setup, the temperature matching was obtained using a closed loop control system to regulate the outer heater power.

The temperature difference between the inner disk and the external annulus was measured by means of a copper/constantan thermopile. The thermopile signal was then used as a feedback in the closed loop control system of the guard ring. The disks are linked together by thermally insulating supports, in fact any thermal shunt between the central disk and other parts is minimized so that power measurement errors can be minimized too. The measuring system is placed inside a thermal chamber in which pressure can be varied at different levels. During the testing pressure was kept to the ambient value. The test setup is shown in Fig. 2. Samples were mounted between the cold plate and an aluminium disk whose top side is coated by a high emissivity Electrodag ${ }^{\circledR} 501$ paint.

Equivalent conductivities and transmittance are determined as:

$\lambda_{e q}=\frac{\phi}{A} \frac{t}{\left(2\left(T_{h}-T_{c}\right)\right)}$

$\mathrm{U}_{e q}=\frac{\phi}{A} \frac{1}{\left(2\left(T_{h}-T_{c}\right)\right)}$

$\phi$ is the measured heat flow rate, $A$ is the disk area and $T_{h}$ is the internal disk temperature. At each acquisition the measured parameters are the plate, disk and heater temperatures, the inner supply voltage $\left(V_{0}\right)$ and current $\left(i_{0}\right)$ and the thermopile voltage for the control loop strategy. The hot and cold temperatures were measured using thermocouples (grade 3, type K). Measurements were acquired by a 34970A Agilent multiplexer and heater was controlled by National Instruments PCI-MIO-16E-4 input/output board. Data were stored in a computer that also controlled the Agilent E3615A DC power supplies, through the acquisition board. Schematic of the measurement/acquisition chain is provided in Fig. 3.

The temperature was set at two different values, i.e. 40 and $60^{\circ} \mathrm{C}$ whereas the cold interfaces were kept at ambient temperature. Measurements have been taken when the steady state condition was reached.

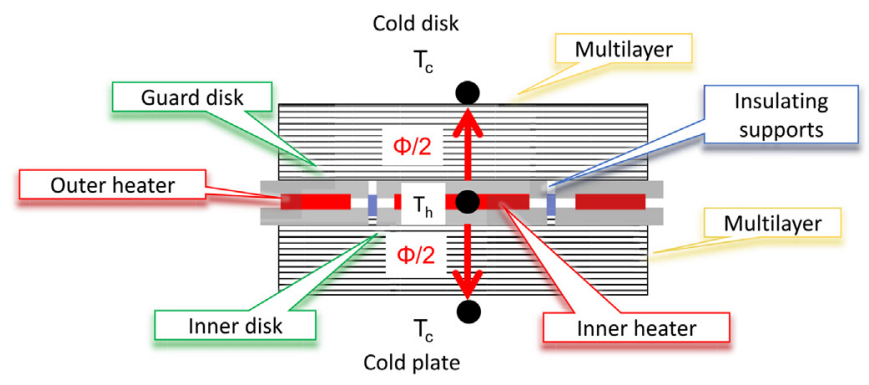

Fig. 1. Sketch of the hot guarded apparatus with two specimens configuration. 

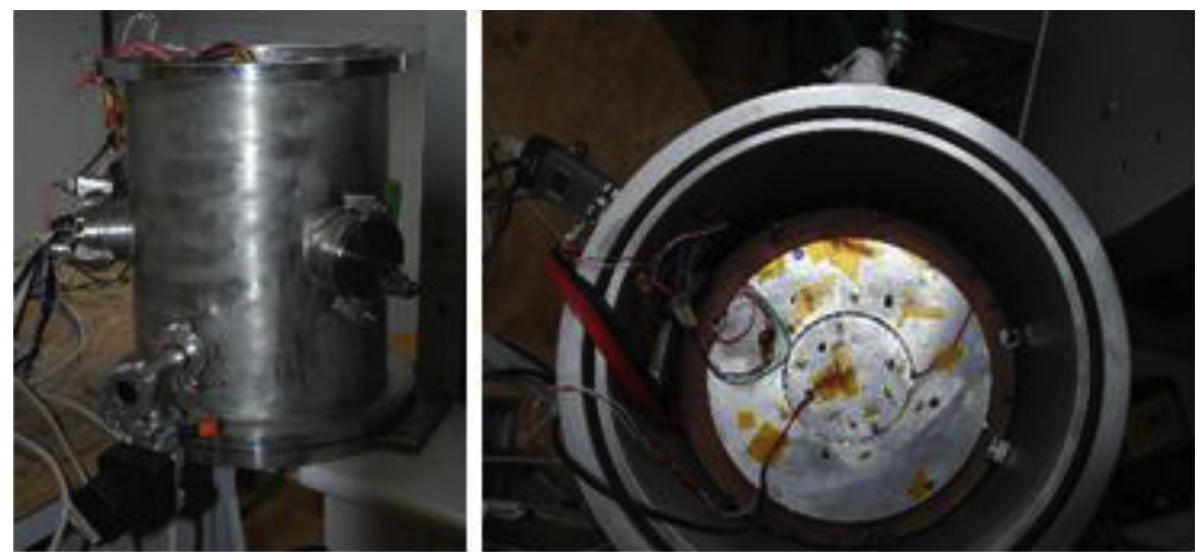

Fig. 2. Pictures of the setup to measure material conductivity.

\subsection{Specimens description}

Tested MLI is ACTIS TRISO Super 10, which is made of layers of aluminium/plastic type reflective foil, separated by layers of plastic bubble wrap or foam material [10]. A picture of the specimen is shown in Fig. 4. Specimen size is about $16 \mathrm{~cm}$ width and $16 \mathrm{~cm}$ length. Overall thickness of the specimen is about $25 \mathrm{~mm}$. Technical characteristic of the test product are summarized in Table 1.

Beside the MLI specimen, a sample of the composite insulating system, hereafter renamed Thermo Reflective Multilayer System (TRMS), was manufactured as well. Scheme of the TRMS structure and view of one of the tested prototype are provided in Fig. 5.

The TRMS comprises an ACTIS multilayer sample combined with vulcanized rubber spacers to guarantee an air gap of $10 \mathrm{~mm}$ thickness on each side, and a polyester membrane to enclose the overall system. Thus, the overall thickness of the sample is about 45 $\mathrm{mm}$. The covering material was selected thanks to its high flexibility, resistance, cheapness and lightness. In fact, polyester provides $180 \mathrm{~g}$ of mass per square meter, a tensile strength of 100 $\mathrm{N}$ longitudinally and, $150 \mathrm{~N}$ transversely. Vulcanized rubber allows achieving low weight, with density between 0.9 and $1.5 \mathrm{~kg} / \mathrm{dm}^{3}$, and furnishes a low thermal conductivity, about $0.15 \mathrm{~W} /\left(\mathrm{m}^{\circ} \mathrm{C}\right)$. The intended structure would provide the thermal insulation and flexibility required to handle and assemble the MLI. The specimen area (10 $\mathrm{mm}$ width and $16 \mathrm{~mm}$ length) does not touch the external annulus, so that any lateral heat flow is avoided. Two samples of the TRMS (one is shown in Fig. 5b) were manufactured and tested with the hot guard plate apparatus.

\subsection{Uncertainty evaluation}

Uncertainties of the measured conductivity and transmittance are derived by propagating each uncertainty contribution of the parameters of Eq. (4) and Eq. (5), i.e. the sample geometry, the

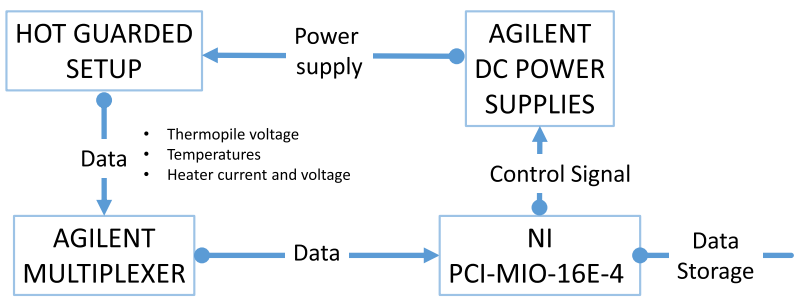

Fig. 3. Sketch of the measurement chain for thermal conductivity/conductance testing. temperature and the heat flow rate. Thus, according to the ISOGUM standard [35] the conductivity uncertainty can be found as:

$\frac{u_{\lambda_{e q}}}{\lambda_{e q}}=\sqrt{\left(\frac{u_{\phi_{t}}}{\phi_{t}}\right)^{2}+\left(\frac{u_{A}}{A}\right)^{2}+\left(\frac{u \Delta_{T}}{\Delta_{T}}\right)^{2}+\left(\frac{u_{t}}{t}\right)^{2}}$

In similar manner, uncertainty of the equivalent transmittance can be found as:

$$
\frac{u_{U_{e q}}}{U_{e q}}=\sqrt{\left(\frac{u_{\phi_{t}}}{\phi_{t}}\right)^{2}+\left(\frac{u_{A}}{A}\right)^{2}+\left(\frac{u \Delta_{T}}{\Delta_{T}}\right)^{2}}
$$

The uncertainty of $\Delta_{T}$, difference between testing temperatures $T_{h}$ and $T_{c}$, is derived as:

$u_{\Delta_{T}}=\sqrt{\left(\frac{\partial \Delta_{T}}{\partial T_{c}} u_{T_{c}}\right)^{2}+\left(\frac{\partial \Delta_{T}}{\partial T_{h}} u_{T_{h}}\right)^{2}}$

$u_{T h}$ and $u_{T c}$ are respectively the temperature uncertainties for the inner disk and the cold plate and disk. Given that the temperatures are measured by type $\mathrm{K}$ thermocouples, the maximum error is 2.6 ${ }^{\circ} \mathrm{C}$ in the range between -40 and $375{ }^{\circ} \mathrm{C}$ [36]; this value in-cludes the contribution of the reference joint whose temperature was measured with a grade A Pt100 platinum resistance ther-mometer. Inner disk area and specimen thickness have been measured by means of a caliper with a resolution of $0.05 \mathrm{~mm}$, thus an uncertainty of $0.015 \mathrm{~mm}$ affects specimen geometry measurement. Heat flow-rate measurements accuracy is related to the supply voltage and current measurements performed with the Agilent unit. The heat flow rate uncertainty is computed as:

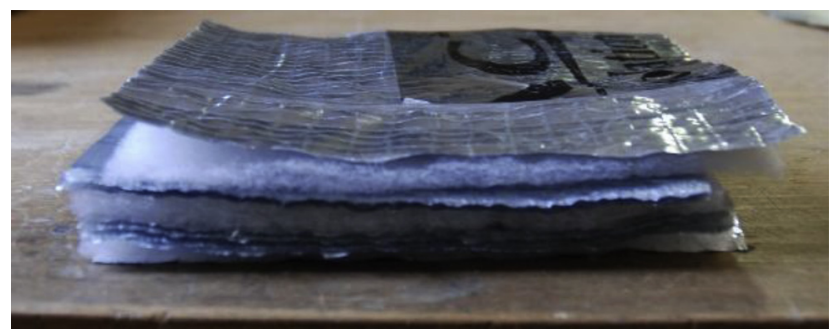

Fig. 4. View of the multilayer sample. 
Table 1

Technical data of the tested multilayer.

\begin{tabular}{lll}
\hline & Values & Standard \\
\hline Thickness & $25.00 \mathrm{~mm}$ & EN 823 \\
Thermal resistance & $5.25 \mathrm{~m}^{2}{ }^{\circ} \mathrm{C} / \mathrm{W}$ & BIP-001 \\
Air permeability & Impermeable & EN 12114 \\
Emissivity of aluminium foil & 0.05 & EN 16012 \\
Water vapor resistance & $>500 \mathrm{MN} \cdot \mathrm{s} / \mathrm{g}$ & EN 1931 \\
Watertight & W1 & EN 1928 method A \\
& & EN 13859-1 \\
Weight per square meter & $\geq 0.738 \mathrm{~kg} / \mathrm{m}^{2}$ & Not defined \\
Reaction to fire & Class F & EN 13501-1 \\
\hline
\end{tabular}

$u_{\phi}=\sqrt{\left(\frac{\partial \phi}{\partial V_{0}} u_{V_{0}}\right)^{2}+\left(\frac{\partial \phi}{\partial i_{0}} u_{i_{0}}\right)^{2}}$

where $u_{V 0}$ and $u_{i 0}$ are the uncertainties of the supply voltage and current of the central heater, respectively. Preliminary analyses evidenced that the main contributions to the uncertainty in Equations (6) and (7) are due to the temperature and heat flow rate uncertainties. Relative uncertainty about geometry measurement is around $0.1 \%$ and therefore, no significant differences are expected between the conductivity and transmittance relative uncertainties.

\section{Results and discussion}

Measured equivalent conductivity and transmittance for both the MLI and the TRMS are provided in Table 2.

At $40{ }^{\circ} \mathrm{C}$, results show for the multilayer specimen a thermal conductivity of $0.040 \mathrm{~W} /\left(\mathrm{m}^{\circ} \mathrm{C}\right)$ and an equivalent transmittance set to about $1.6 \mathrm{~W} /\left(\mathrm{m}^{2}{ }^{\circ} \mathrm{C}\right)$. Relative uncertainties for multilayer and TRMS are set to $4 \%$, both for the thermal conductivity and the transmittance. The measured conductivity slightly increases at higher disk temperature. This can be partially justified by air conductivity increasing within the investigated temperature range. Anyway, given that the measurement uncertainty is of about $4 \%$, the two equivalent conductivities are fully compatible. Moreover, the measured conductivity is compatible with the technical datasheet of the multilayer manufacturer and previous studies [4], where conductivity varies between 0.033 and $0.047 \mathrm{~W} /\left(\mathrm{m}^{\circ} \mathrm{C}\right)$. In similar working condition, the TRMS provides better performances, as testified by the computed equivalent transmittance. The equivalent conductivity of the TRMS sample in Table 2 has been computed knowing the sample thickness of the insulating system. Measured transmittance is lower than ones found in literature related to similar insulators, which shows values between 1.66 and $2.12 \mathrm{~W} /\left(\mathrm{m}^{2}{ }^{\circ} \mathrm{C}\right)$ in case of hot guarded hot plate testing [4]. Obtained
Table 2

Measured thermal conductivity and transmittance of the multilayer and TRMS.

\begin{tabular}{llll}
\hline Th $\left[{ }^{\circ} \mathrm{C}\right]$ & Multilayer & & $\frac{\text { TRMS }}{40}$ \\
\cline { 2 - 3 } & 40 & 60 & 0.038 \\
\hline$\lambda_{\mathrm{eq}}\left[\mathrm{W} /\left(\mathrm{m}^{\circ}{ }^{\circ} \mathrm{C}\right)\right]$ & 0.040 & 0.042 & 0.85 \\
$\mathrm{U}_{\mathrm{eq}}\left[\mathrm{W} /\left(\mathrm{m}^{2}{ }^{\circ} \mathrm{C}\right)\right]$ & 1.607 & 1.690 & 1.183 \\
$\mathrm{R}_{\mathrm{eq}}\left[\left(\mathrm{m}^{2}{ }^{\circ} \mathrm{C}\right) / \mathrm{W}\right]$ & 0.623 & 0.592 & \\
\hline
\end{tabular}

result is encouraging, given that the air thickness of the TRMS sample is relative small whereas better performances can be achieved enlarging its air cavities, e.g. up to $2.5 \mathrm{~cm}$ [17]. Thus, the TRMS final design can be further enhanced to improve its insulating performances. Summarizing, the experimental results underline that the design of a building element based on the TRMS can ensure an adequate thermal performance providing at the same time a lightweight, flexible and cheap system. All these characteristics match with the typical needs in current global problem of disasters, target of the proposed work.

\section{The architectural application: the Air Shelter house panel}

Analysing the past experience concerning disasters, it happens that housing programmes can take many years to complete, especially when a large number of houses are involved. However, in these critical conditions is essential providing the victims' needs as soon as possible. The transitional shelters are generally converted in permanent ones even if they do not have appropriate requisites [3]. In fact, it is important that the shelter design is made following the cultural, social and economic backgrounds of the specific disaster-affected societies, and even if the design is based on rapid and cost effective solutions, it has to be accepted by the population culture.

The project Air Shelter house is based on above considerations and proposes a building panel made of TRMS, which can be assembled with punctual or continuous masonry structures or can be exploited to build lightweight tents. The building element, in fact, has a modular system that ensures different combination between the panels. Modularity allows creating new buildings according to local construction techniques (Fig. 6a), renovating existing systems like containers or fast assembling temporary constructions as in tents (Fig. $6 \mathrm{~b}$ and c).

Considering the possibility of using containers for the transport, or as housing system itself, the ISO 6346 [37] defines standard size of each building component, with the dimensions of $1.1 \times 0.8 \times$ $0.065 \mathrm{~m}$. Considering the bands placed in the shortest sides, the total dimensions become $1.30 \times 0.80 \times 0.065 \mathrm{~m}$, comprehensive of vulcanized rubber and polyester joints.

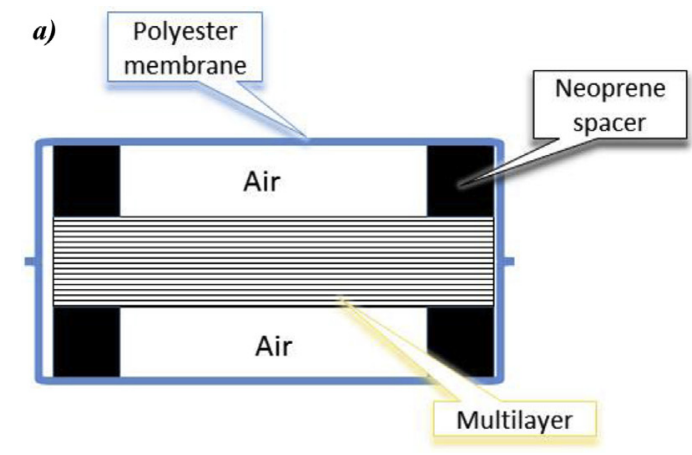

b)

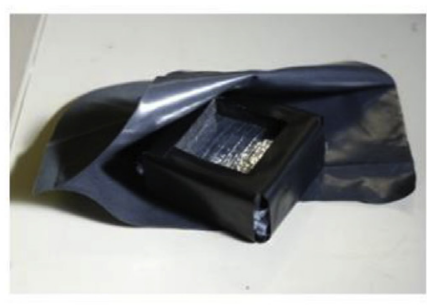

Fig. 5. a) TRMS structure and b) TRMS manufactured prototype. 
a)

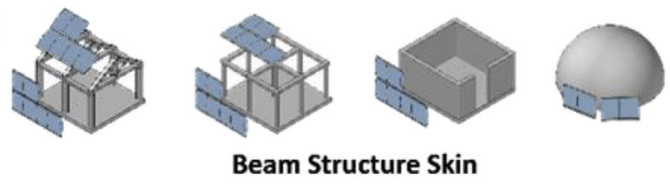

b)

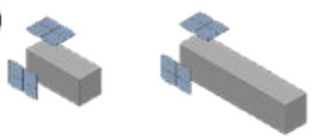

Container Skin
Ca)

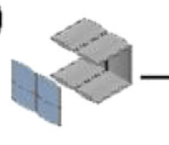

C)

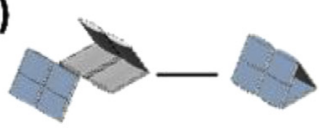

Tent Systems

Fig. 6. Air Shelter applications: a) beam structure skins, b) container covering, c) tents panels.

As shown in Fig. 7, connection between rubber elements of different panels is made with tongue and groove joints that provide good static resistance during disaster. Polyester extremities are designed with strips whose length is about $10 \mathrm{~cm}$ and with neoprene gaskets to provide perfect contact between the two sides of the panel and to hold the MLI. Connection of the polyester extremities is ensured by snaps or zipper, easy to use and assemble.

Different technological solutions have been studied for the panels junction in order to allow applicability at different scenarios. Concieved applications are summarized in Fig. 8. Vertical/horizontal and corner structure joining are designed with modular solutions, investigating different combinations. Connection with the supporting structure is assured by aluminum joints and bands. They are fixed to the vulcanized rubber profile by M10 self-tapping screws dimension $50 \times 26 \mathrm{~mm}$, with self-locking nut and double washers for the contact with the synthetic material. In similar manner the internal multilayer is connected to the rubber profiles through M5 self-tapping screws $60 \times 16 \mathrm{~mm}$, with self-locking nut and double washers. Joints between panels are in aluminum to ensure lightness and the panels are connected by tissue bands, which fit the envelope of the covered structures.

Selection of lightweight materials for the TRMS structure allows easy transport of each module. Moreover, when the air is removed from the system the Air Shelter can be rolled and easily moved: the panel weight reduces to $0.608 \mathrm{~kg}$ and dimensions of the roll are $45 \mathrm{~cm}$ width, $6 \mathrm{~cm}$ thickness and $1.10 \mathrm{~m}$ length. In that case, size of the smallest standard containers [37] would allow packing about
240 panels. Moreover, thanks to the small dimensions, packing can be performed only by one persons and transported by containers (trucks or helicopters) or by small trucks.

Summarizing, the Air Shelter panel offers several advances on existing systems, i.e. easy assembling, integration or replacing of normal tent structure and employment of high insulation performance materials that can be also used in buildings later reconstruction phases.

\section{Tent prototype energy modelling}

A thermal model of one envisaged application of the Air Shelter, i.e. an emergency tent, is hereafter described. The tent is $5.80 \mathrm{~m}$ length and $5.10 \mathrm{~m}$ width, with a medium internal height of $2.20 \mathrm{~m}$ (Table 3). The modelled tent, shown in Fig. 9, accommodates 10 persons in a volume of $59.40 \mathrm{~m}^{3}$ [38]. The total surface area of the model is equal to $96.8 \mathrm{~m}^{2}$. Dynamic analyses have been performed with Trnsys v.17 Environment [39], considering the location of Belgrade. Climate data are derived from Meteonorm database [40] simulating a winter scenario (during January). The model allows predicting the internal temperature for free-running operation (without heating systems) and the heating energy demand to maintain a constant internal temperature of $19^{\circ} \mathrm{C}$.

Starting from the same geometrical model, the dynamic thermal analyses allow comparison between different tent's envelopes. The energy model is represented by one thermal node simulated using Type 56. The envelope is modelled without transparent parts in

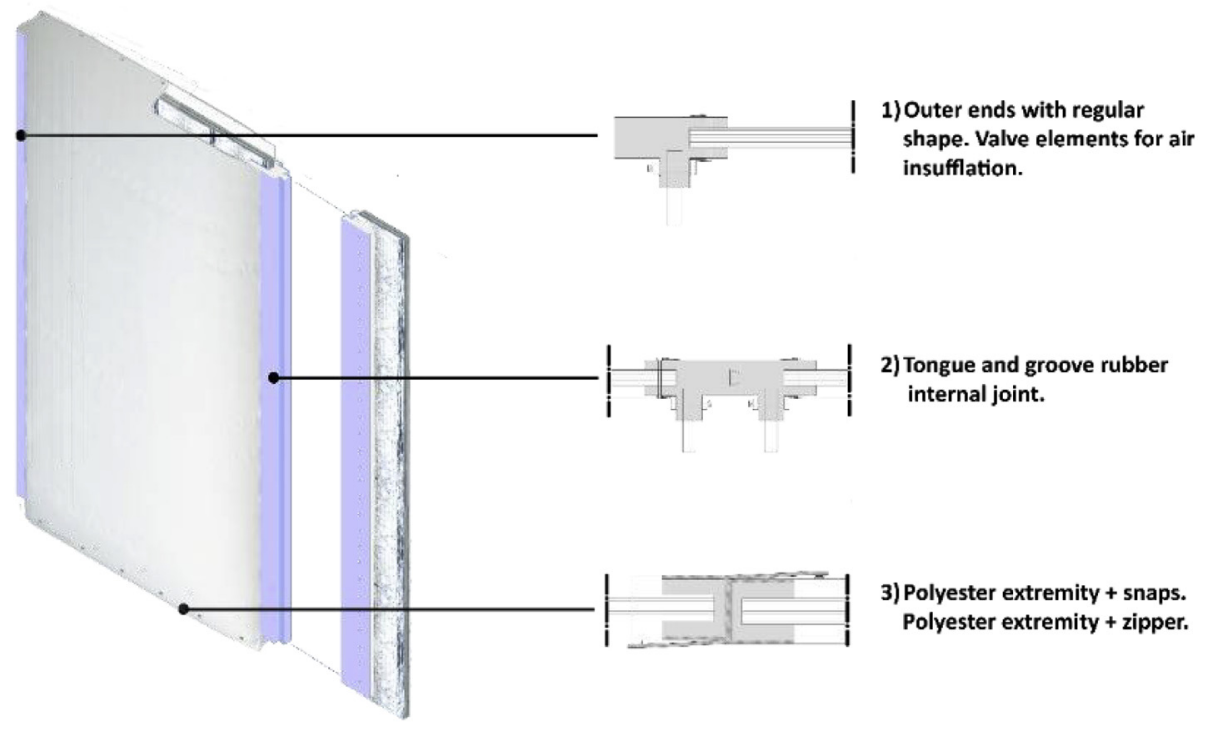

Fig. 7. Air Shelter panel details. 
a) Vertical/Horizontal

Tongue and groove joint

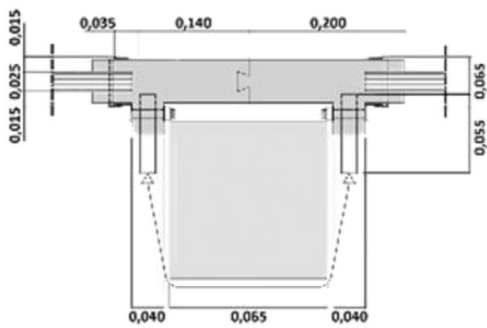

c) Vertical/Horizontal Polyester joint + snaps b) Corner

Tongue and groove joint

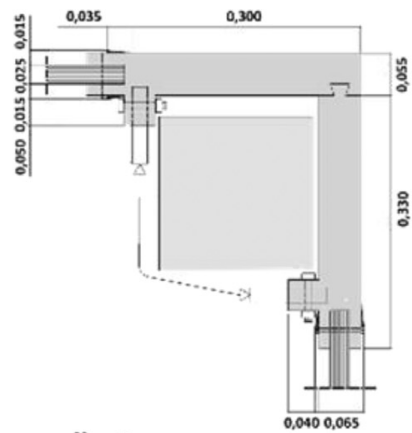

d) Corner

Polyester joint + snaps
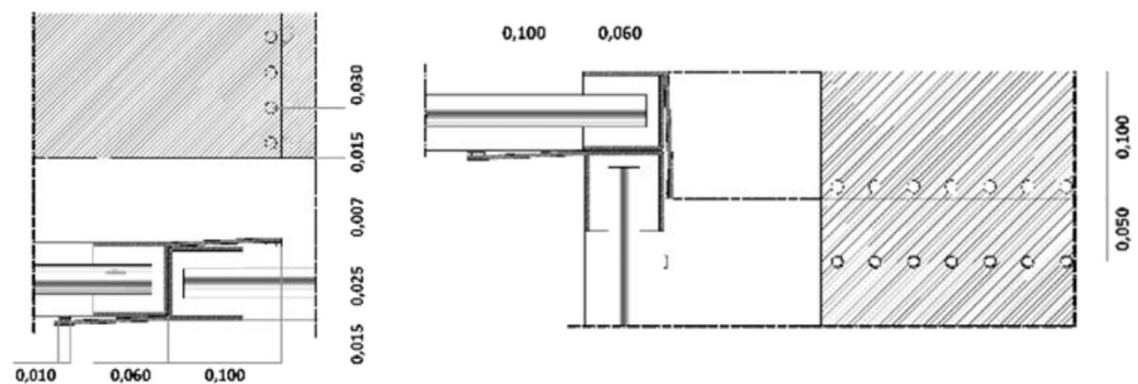

Fig. 8. Pre-design of the joints between Air Shelter panels.

Table 3

Geometric characteristic of the simulated tent.

\begin{tabular}{llllll}
\hline & Length $[\mathrm{m}]$ & Width $[\mathrm{m}]$ & Height $[\mathrm{m}]$ & Area $\left[\mathrm{m}^{2}\right]$ & Volume $\left[\mathrm{m}^{3}\right]$ \\
\hline Floor & 5.80 & 5.10 & & 29.58 & \\
Wall/Roof & & & 2.20 & 64.96 & \\
Door/exit & & & & 2.28 & \\
Volume & & & & & 59.40 \\
\hline
\end{tabular}

order to reduce the solar gains that may lead to misleading results about the opaque envelope performance. The "wall" and "roof" is simulated considering a solar absorbance coefficient of 0.4 (clear colour) and the convective heat transfer coefficients are set to $3.05 \mathrm{~W} /\left(\mathrm{m}^{2}{ }^{\circ} \mathrm{C}\right)$ for internal surfaces and $17.8 \mathrm{~W} /\left(\mathrm{m}^{2}{ }^{\circ} \mathrm{C}\right)$ for the external ones. These values are assumed constant for all the simulation time and for all the case studied.

Contact between tent floor and ground is simulated with the ground coupling model Type 49. This component models the soil beneath a zone building (Type 56). The model takes the heat transfer into the building at the outside surface (total convective and long wave radiation gain to outside surface) for the zone, calculates the fully 3-D soil temperature profile, and then outputs the average underfloor surface temperature for the zone. This
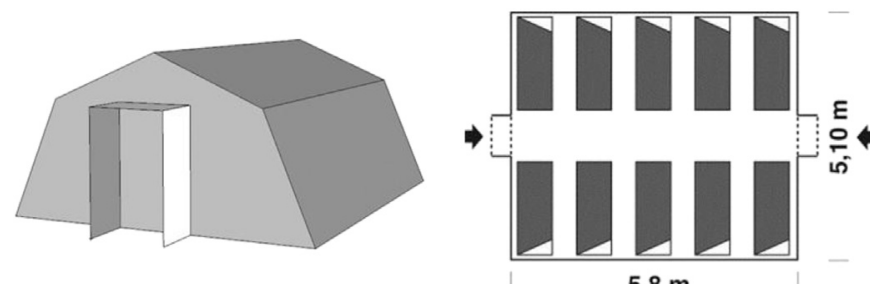

Fig. 9. Tent model. underfloor surface temperature is the input outer surface temperature for the floor of the studied thermal zone.

Three different cases have been studied:

- "Base Case": the relative U-values of the tent envelope have been estimated from literature [20-27] and reported in the Table 4 . The standard UNHCR shelter system is a canvas tent with low thermal resistance leading to large heat losses through conduction, convention and ventilation;

- "Air Shelter" Case 1: the tent model is based on the thermal properties derived by the experimental activity performed in this work. These are summarized in Table 5. The tent is completely made by TRMS (roof, wall and floor elements);

- "Air Shelter" Case 2: the tent roof/wall elements are made of TRMS whereas the floor is composed by LDPE (Low-density polyethylene) membrane and canvas exposed to inner side.

Table 4

Thermal properties of the fabric conductance calculation of the UNHCR emergency canvas tent. The difference in air thermal resistance values is due to convective air movement assumption.

\begin{tabular}{llll}
\hline & Thickness $[\mathrm{mm}]$ & $\mathrm{R}\left[\left(\mathrm{m}^{2}{ }^{\circ} \mathrm{C}\right) / \mathrm{W}\right]$ & $\mathrm{U}_{\text {eq }}\left[\mathrm{W} /\left(\mathrm{m}^{2}{ }^{\circ} \mathrm{C}\right)\right]$ \\
\hline Floor & & & \\
Rsi & & 0.15 & \\
LDPE & 0.25 & 0.00625 & \\
Canvas & & 0.000035 & \\
Total R & $\sim \mathbf{0 . 1 5 6}$ & $\sim \mathbf{6 . 4 1}$ \\
Wall/Roof & & \\
Rsi & 0.123 & \\
Cotton & 0.0139 & \\
Air & 0.192 & \\
Canvas & 0.054 & \\
Air cavity & $0.15^{*}$ & \\
Canvas & 0.054 & $\mathbf{1 . 5 2}$ \\
Rse & 0.03 & \\
Total R & $\mathbf{0 . 6 5 8}$ & \\
\hline
\end{tabular}


Table 5

Thermal properties of the Air Shelter (Case 1 and Case 2) models.

\begin{tabular}{llll}
\hline & Thickness $[\mathrm{mm}]$ & $\mathrm{R}\left[\left(\mathrm{m}^{2}{ }^{\circ} \mathrm{C}\right) / \mathrm{W}\right]$ & $\mathrm{U}_{\mathrm{eq}}\left[\mathrm{W} /\left(\mathrm{m}^{2}{ }^{\circ} \mathrm{C}\right)\right]$ \\
\hline Floor & & & \\
Rsi & 0.00025 & 0.15 & \\
LDPE & & 0.00625 & \\
TRMS & 1.183 & $\sim \mathbf{0 . 7 4 7}$ \\
Total R & $\sim \mathbf{1 . 3 3 9}$ & \\
Wall/Roof & & \\
Rsi & 0.123 & \\
TRMS & 1.183 & $\mathbf{0 . 7 4 9}$ \\
Rse & 0.03 & \\
Total R & $\mathbf{1 . 3 3 6}$ & \\
\hline
\end{tabular}

Thermal dynamic simulations have been performed with the following parameters:

- internal gains related to the persons inside the tent, set to $800 \mathrm{~W}$ from $18 \mathrm{PM}$ to $7 \mathrm{AM}$ and $200 \mathrm{~W}$ during the rest of the day; the latter value has been assumed under the assumption that refugees stay partly outside or in a community space. The gains are considered $50 \%$ radiative and $50 \%$ convective.

- gains from lights are set to $144 \mathrm{~W}, 80 \%$ radiative and $20 \%$ convective;

- air change per hour $(\mathrm{ac} / \mathrm{h})$ through the tent envelope is set to 4 and 2 respectively for the Base Case and the Air Shelter Case 1 and 2, respectively. These parameters have been selected considering the results in wind tunnel testing carried out by

a)

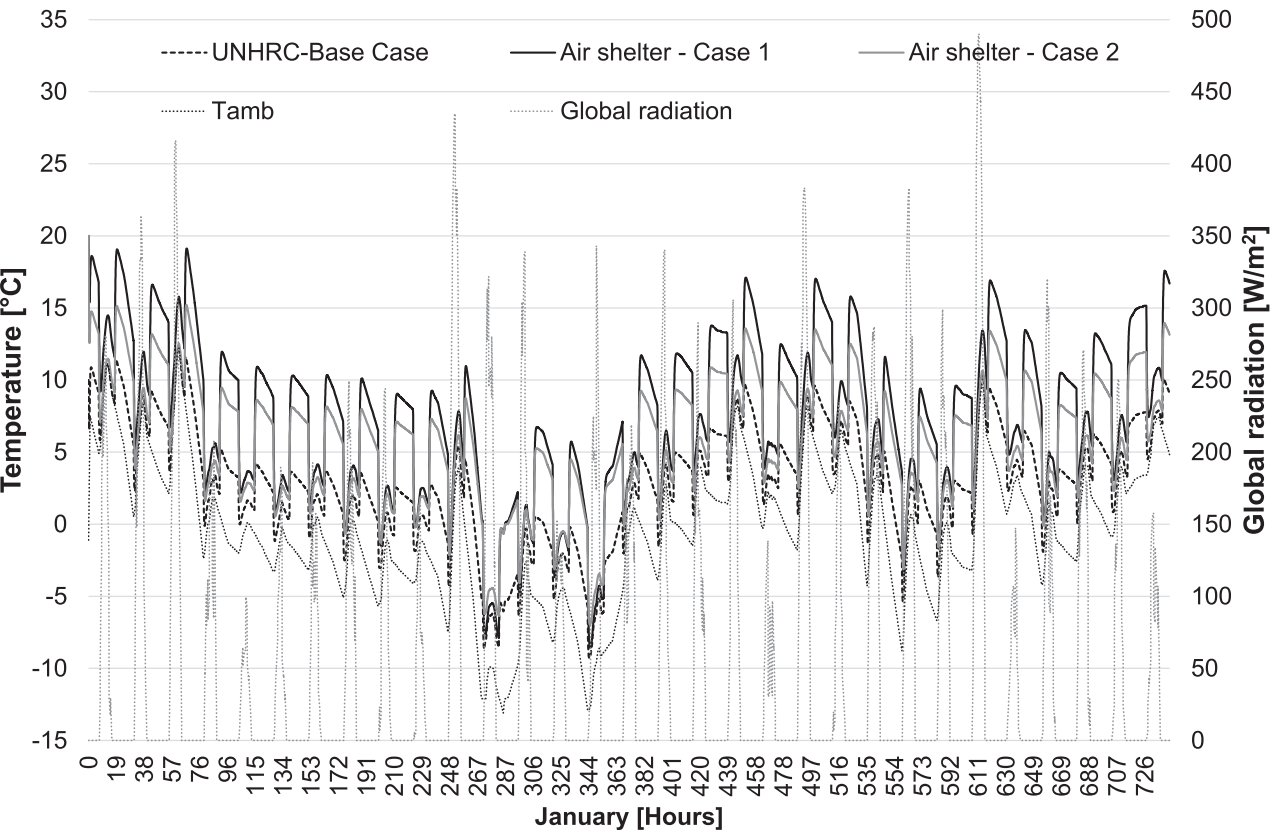

b)

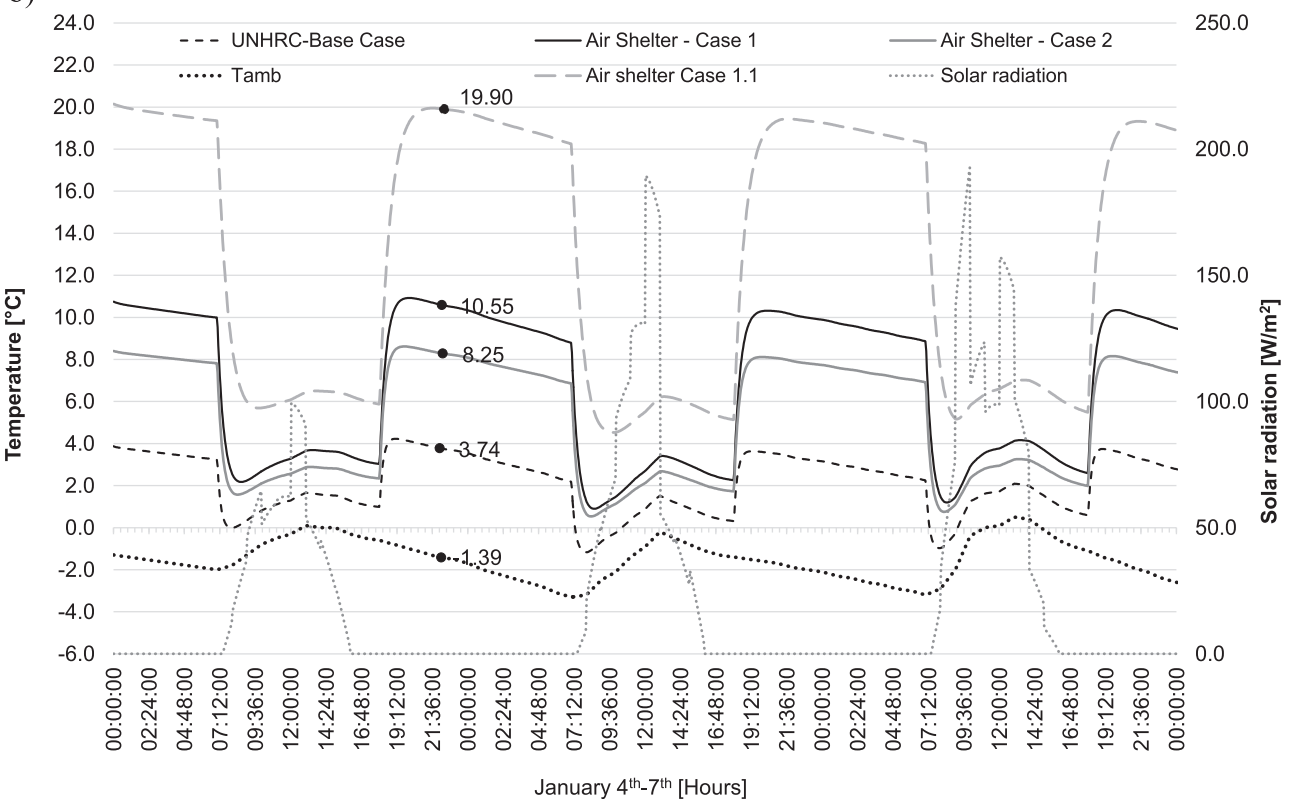

Fig. 10. a) Computed temperatures over the month of January. b) Temperature profiles during the days 4th-7th of January. 


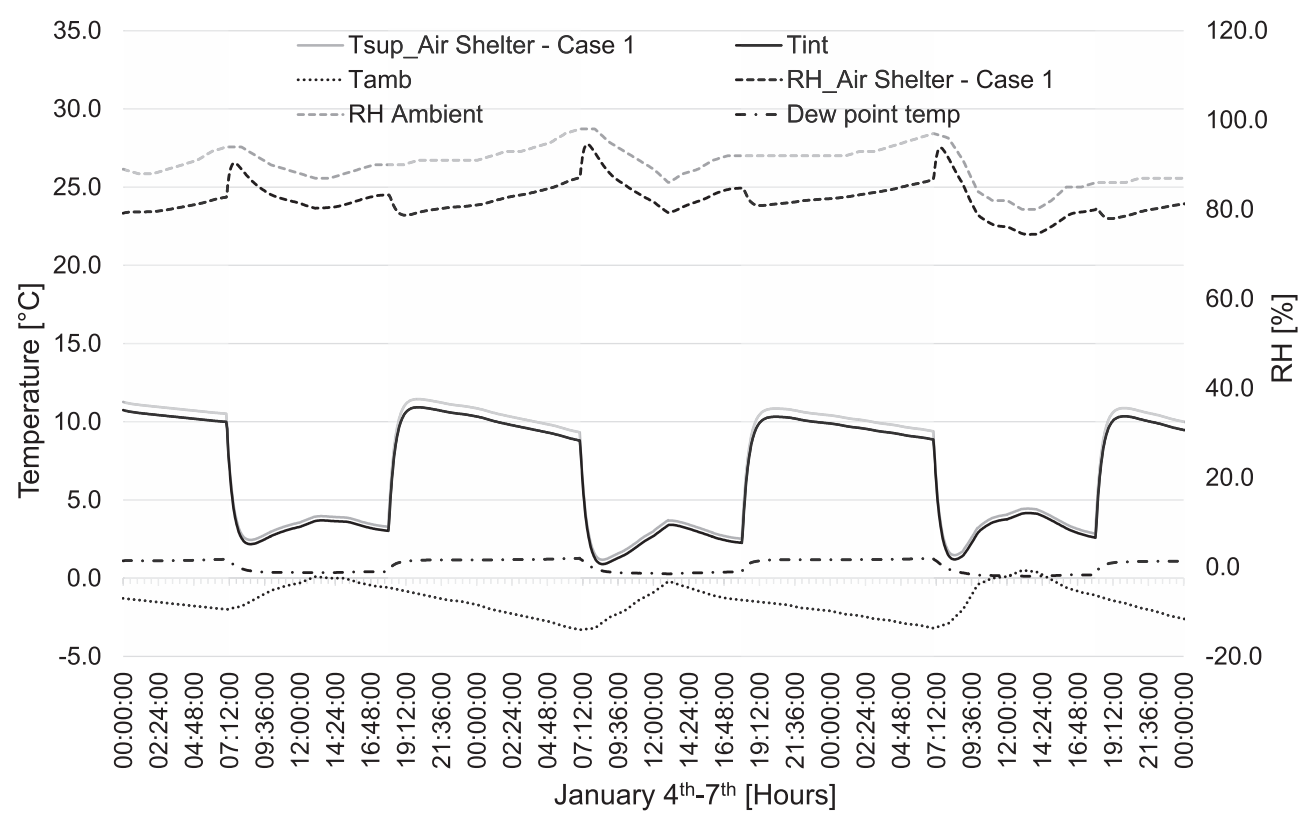

Fig. 11. Surface internal temperature profile (south orientation side) and air humidity profile of the simulated Case 1 .

Mafield [22] and Patangaroa [23] and on the basis of the tent structure. In fact, the Base Case skin is made by cotton and canvas, making the tent thin and also permeable whereas, the Air Shelter (Case 1 and 2) tents minimize the infiltration losses by adopting impermeable and water proof polyester fabrics coupled with MLI. The air infiltration rate have been considered constant during the day.

In order to compare the impact of the different tent's envelope technologies, in each simulated case, the environmental and the simulation condition have been kept constant. Finally, it has to be noticed that for all the above mentioned cases, considering the small area of the joint (related to the total), the material and the typology, as shown in the Fig. 8, the thermal bridges have been neglected. This assumption has to be verified by experimental activity once Air Shelter prototype would be manufactured. Anyway, thermal performances comparison between simulated cases is still valid.

\subsection{Simulation results}

Fig. 10 provides the computed temperatures for the Base Case, Case 1 (Air Shelter Panels for roof/wall and floor) and Case 2 (Air Shelter Panels only in a roof/wall) under the simulated scenario.

Results show that the Air Shelter tents ensure higher internal temperature compared to the Base Case, mainly during night time operation, providing a variable temperature difference according to the weather conditions (ambient air temperature $\mathrm{T}_{\mathrm{amb}}$ and global radiation). The mean temperature difference between the Base Case and Case 1 and 2 is about $7{ }^{\circ} \mathrm{C}$ and $5{ }^{\circ} \mathrm{C}$, respectively. The uninsulated floor (i.e. Case 2 ) provides a temperature reduction of 2 ${ }^{\circ} \mathrm{C}$ with respect to the Case 1 . This is justified by the increased heat dissipation through the ground.

Moreover, Fig. 10 shows that the temperature profiles of all the cases get nearer during the day. This is due to the combination of the air infiltration and internal gain reduction: the first is the main heat dissipation whereas the second is of paramount importance to achieve a comfortable internal temperature, as testified by the temperature drops during the day, about $8{ }^{\circ} \mathrm{C}$. In fact, during the day-time, the temperature difference between the tents reduces to $1.5^{\circ} \mathrm{C}$ and $2{ }^{\circ} \mathrm{C}$.
Humidity analyses have been performed as well in order to understand condensation phenomena. Fig. 11 links the computed surface internal temperature to the air humidity for Case 1 model. Results point out that the internal surface temperature of the tent is higher than the dew temperature, avoiding condensation phenomena during night, i.e. the occupied period.

Fig. 12 shows the energy performance of the simulated cases considering the set point of $19{ }^{\circ} \mathrm{C}$. The numerical results show the following energy needs: about $1225 \mathrm{kWh}$ for the Base Case, 555 $\mathrm{kWh}$ for the Case 2 and $386 \mathrm{kWh}$ for the Case 1 (parameterized to the floor area of the tent respectively equal to $41.43,18.76$ and $13.04 \mathrm{kWh} / \mathrm{m}^{2}$ ). As expected, the increased thermal insulation of the envelope allows high energy saving. With respect to the base case, the heating loads reduction sets to $55 \%$ and $69 \%$ for the Case 2 and the Case 1 , respectively. Considering the fuel oil as energy vectors, the tent prototypes could be heated (considering the month of January), with $0.039 \mathrm{~m}^{3}$ for the Case 1 and $0.055 \mathrm{~m}^{3}$ for the Case 2. These are much lower than the required oil volume in the Base Case, i.e. $0.122 \mathrm{~m}^{3}$. Thus, the energy saving obtained with the new designed emergency system would lead to many benefits, on both the energy procurement and fuel transportation.

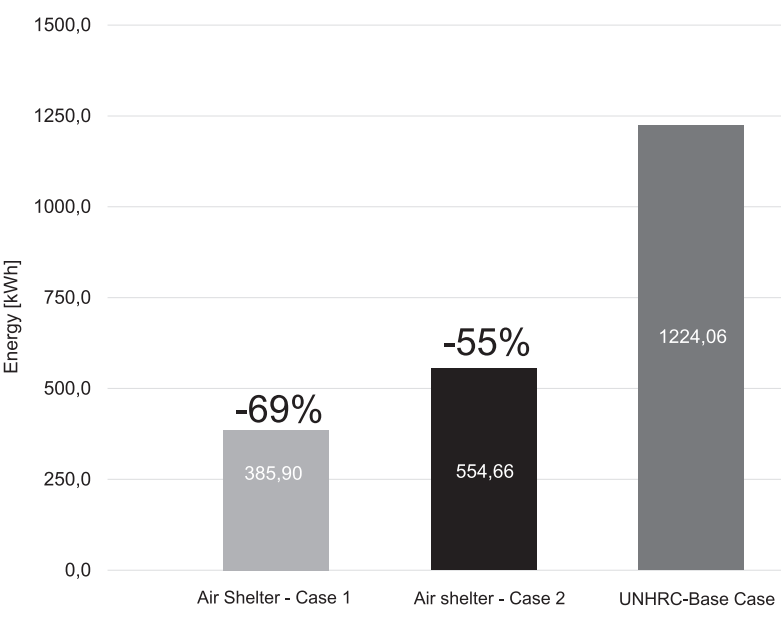

Fig. 12. Potential of the energy saving of the simulated cases. 


\section{Conclusions}

Testing with guarded-hot plate apparatus has been performed at different temperatures on a commercially available MLI to measure its insulating performances, i.e. the equivalent thermal conductivity and transmittance. Results confirmed agreement with literature data, providing at $40{ }^{\circ} \mathrm{C}$ a thermal conductivity and transmittance of about $0.040 \mathrm{~W} /\left(\mathrm{m}^{\circ} \mathrm{C}\right)$ and $1.6 \mathrm{~W} /\left(\mathrm{m}^{2}{ }^{\circ} \mathrm{C}\right)$. Relative measurement uncertainty was found to be around $4 \%$. Tests at $60^{\circ} \mathrm{C}$ evidenced a slight increasing of the thermal conductivity, about $5 \%$. A prototype of an insulating system based on the tested MLI, has been manufactured and tested in similar conditions. The conceived structure has been designed to be the core of an innovative emergency architecture, named Air Shelter, waterproof and flexible building panel. Results showed an enhancement of the thermal performance with respect to the multilayer alone, providing an equivalent transmittance of $0.85 \mathrm{~W} /\left(\mathrm{m}^{2}{ }^{\circ} \mathrm{C}\right)$.

A thermal model of an emergency tent based on the Air Shelter have been developed. Dynamic simulations with Eastern Europe winter scenario (Belgrade, during winter season) carried out on two different tent configurations showed energy savings of 55\% and $69 \%$ with respect to the UNHCR test bench. Even without energy supply (only casual gains), the Air Shelter based tent reaches a superior internal comfort. Moreover, the thermal analyses evidenced the importance of the heat dissipation through the floor, highlighting an additional energy saving of about $14 \%$ with a tent prototype completely insulated by the proposed structure.

Obviously, a comfort based design controls the air infiltration to achieve the best balance between air exchange and internal temperature uniformity. In this respect, the next design stage of the Air Shelter will develop a way of promoting the air exchange by using flues, flaps or holes. Moreover, field tests on an Air Shelter tent prototype are foreseen as next steps of this research activity.

\section{Acknowledgements}

Authors would like to gratefully thank Professor Bortolino Saggin for his contribution.

\section{References}

[1] EmData, 2013, (www.emdat.be)

[2] iDCM 2012, Internal Displacement Monitoring Centre, (www.internaldisplacement.org).

[3] UNHABITAT, Shelter Projects, 2008. unhabitat.org.

[4] M.J. Tenpierik, E. Hasselaar, Reflective multi-foil insulations for buildings: a review, Energ. Build. 56 (2012) 233-243, http://dx.doi.org/10.1016/ j.enbuild.2012.10.003.

[5] G. Hauser, M. Kersken, H. Sinnesbichler, A. Schade, Building components and building elements - experimental and numerical investigations for comparing the thermal performance of infrared reflecting insulation and of mineral wool, Energ. Build. 58 (2013) pp.131-140, http://dx.doi.org/10.1016/ j.enbuild.2012.10.033

[6] Z. Pasztory, P.N. Peralta, I. Peszlen, Multi-layer heat insulation system for frame construction buildings, Energ. Build. 43 (2011) 713-717, http:// dx.doi.org/10.1016/j.enbuild.2010.11.016.

[7] D.G. Gilmore, Spacecraft Thermal Control Handbook, in: Fundamental Technologies, second ed. Volume I, The Aerospace Press, El Segundo, CA, 2002.

[8] D. Scaccabarozzi, B. Saggin, M. Tarabini, Thermal insulators' performances in simulated Mars environment, J. Heat. Trans-T ASME 136 (2014) 1-6, http:// dx.doi.org/10.1115/1.4025367.

[9] P. Li, H. Cheng, Thermal analysis and performance study for multilayer perforated insulation material used in space, Appl. Therm. Eng. 26 (2006) 2020-2026, http://dx.doi.org/10.1016/j.applthermaleng.2006.01.004.

[10] BM TRADA, Q-mark Registration Schedule, Certificate number BIPS-0105, 2012, www.actis-isolation.com/documentations/144pdf1.pdf

[11] Reflective Insulation Manufacturers Association International (RIMA-I), Reflective Insulation, Radiant Barriers and Radiation Control Coatings, RIMA-I, Olathe, KS, 2002. www.rimainternational.org/pdf/handbook.pdf.
[12] T.I. Ward, S.M. Doran, The Thermal Performance of Multi-foil Insulation, Report BRE, Scotland, Glasgow, 2005, www.planningportal.gov.uk/uploads/br/ multi-foil-insulation_july2005.pdf.

[13] G. Rooney, Thermal insulation Performance Appraisal 139b \& 141b Victoria Road Torry Aberdeen, Report Number 25035, Alba Building Sciences Ltd, 2006, www.insulation-actis.com/pdf/albareport-firststudy.pdf.

[14] J. Seriacaroupin, F. Miranville, D. Braga, M. Duran, Experimental evaluation of the thermal performance of a building roof including a multireflective radiant barrier, Sun City, in: 5th International Conference on Heat Transfer, Fluid Mechanics and Thermodynamic SJ7, SAF, 1-4 July, 2007.

[15] F. Miranville, A.H. Fakra, S. Guichard, H. Boyer, J.P. Praene, D. Bigot, Evaluation of the thermal resistance of a roof-mounted multi-reflective radiant barrier for tropical and humid conditions : experimental study from field measure-ments, Energ. Build. 49 (2012) 79-90, http://dx.doi.org/10.1016/ j.enbuild.2012.01.013.

[16] F. Eoghan, Thermal Testing of Innovative Building Insulations (Master thesis), Dublin Institute of Technology, 2009 (arrow.dit.ie/engmas/33).

[17] H.H. Saber, Investigation of thermal performance of reflective insulations for different applications, Energ. Build. 52 (2012) 32-44, http://dx.doi.org/ 10.1016/j.buildenv.2011.12.010.

[18] CSTB, Annual Report 2007, Marne-la-Valee, 2007, www.cstb.fr/fileadmin/ documents/webzines/anglais/PDF/CSTB-RA07UK-pages2bis.pdf.

[19] W. Wei, X. Li, R. Wang, Y. Li, Effects of structure and shape on thermal performance of perforated multi-layer insulation Blankets, Appl. Therm. Eng. 29 (2009) 1264-1266, http://dx.doi.org/10.1016/j.applthermaleng.2008.06.024.

[20] UNHCR family tent description, (www.unhcr.org).

[21] R. Ajam, Thermal Comfort in Low-cost Refugee Shelters: A Computer Simulation Study in Waqas, A Lower Desert Valley Area in Jordan, UNRWA-HQ Amman, 1999 (Master thesis).

[22] P. Manfield, Modelling of a Cold Climate Emergency Shelter: Prototype and Comparison with the United Nations Winter Tent, The Martin Centre, Cambridge, 2000. www.shelterproject.org/downloads/manfield2.pdf.

[23] R. Potangaroa, Climate Responsive Design Tools for Emergency Shelter, IASC Working Group, November 2005. Report of Emergency Shelter Cluster, www. sheltercluster.org.

[24] M.N. Pilsworth, The Calculation of Heat Loss from Tents, Technical report TR-79/017, United States Army, September 1978, www.dtic.mil/dtic/tr/ fulltext/u2/a072415.pdf.

[25] C. Crawford, P. Manfield, A. McRobie, Assessing the thermal performance of an emergency shelter system, Energ. Build. 37 (2005) 471-483, http://dx.doi.org/ 10.1016/j.enbuild.2004.09.001.

[26] R. Battilana, Design of Cold Climate Temporary Shelter for Refugees, University of Cambridge, 2001. Master thesis, www.shelterproject.org/downloads/ cold\%20climate\%20liner.pdf.

[27] S.N. Flanders, Cold Regions Testing of an Air-transportable Shelter, Special Report 81-16 United States Army Corps of Engineers, Cold Regions Research and Engineering Laboratory, 1981. oai.dtic.mil/oai/oai? verb $=$ getRecord \&metadataPrefix $=$ html\&identifier=ADA107131

[28] D. Salmon, Thermal conductivity of insulations using guarded hot plates including recent developments and sources of reference materials, Meas. Sci. Technol. 12(12)(2001) 89-98, http:// dx.doi.org/10.1088/0957-0233/12/12/201.

[29] L.M. Al-Hadhrami, A. Ahmad, Assessment of thermal performance of different types of masonry bricks used in Saudi Arabia, Appl. Therm. Eng. 29 (2009) 1123-1130, http://dx.doi.org/10.1016/j.applthermaleng.2008.06.003.

[30] J.L. Vivancos, J. Soto, I. Perez, J.V. Ros-Lis, R. Martinez-Manez, A new model based on experimental results for the thermal characterization of bricks, Build. Environ. 44 (5) (2009) 1047-1052, http://dx.doi.org/10.1016/ j.buildenv.2008.07.016

[31] A. Franco, An apparatus for the routine measurement of thermal conductivity of materials for building application based on transient hot-wire method, Appl. Therm. Eng. 27 (2007) 2495-2504, http://dx.doi.org/10.1016/ j.applthermaleng.2007.02.008.

[32] S.A. Al-Ajlan, Measurements of thermal properties of insulation materials by using transient plane source technique, Appl. Therm. Eng. 26 (2006) 2184-2191, http://dx.doi.org/10.1016/j.applthermaleng.2006.04.006.

[33] ASTM C177 - 13, Standard Test Method for Steady-state Heat Flux Measurements and Thermal Transmission Properties by Means of the GuardedHot-Plate Apparatus.

[34] ISO 8302, Thermal insulation, Determination of Steady-state Thermal Resistance and Related Properties - Guarded Hot Plate Apparatus, 1991.

[35] ISO/IEC guide 98, Guide to the Expression of Uncertainty in Measurement (GUM), 1993.

[36] IEC 60584-2, International Thermocouple Reference Tables. Specification for Thermocouple Tolerances, 1982.

[37] ISO6346, Containers Code: Size and Type for Intermodal Shipping Containers, 1995.

[38] Montana 29 tent Catalog, 2014. www.ferrino.it

[39] TRNSYS, A Transient System Simulation Program, University of Wisconsin, Madison, 2006.

[40] Meteonorm, Global Meteorological Database for Engineers, Planners and Education, Version 5.1 - Edition, 2005, www.meteonorm.com. 